\title{
HUBUNGAN KEDALAMAN PIRIT DENGAN BEBERAPA SIFAT KIMIA TANAH DAN PRODUKSI KELAPA SAWIT (Elais guineensis)
}

\section{Pyritic Depth Relationship with Some Soil Chemical Properties and Oil Palm Production}

\author{
Atang Sutandi1 ${ }^{*}$, Budi Nugroho'), Bayu Sejati2) \\ 1) Departemen Ilmu Tanah dan Sumberdaya Lahan, Fakultas Pertanian, IPB, Jl. Meranti Kampus IPB Darmaga, \\ Bogor 16680 \\ 2) Alumni Program Studi Manajemen Sumberdaya Lahan, Departemen Ilmu Tanah dan Sumberdaya Lahan, \\ Fakultas Pertanian, IPB, Jl. Meranti Kampus IPB Darmaga, Bogor 16680
}

\begin{abstract}
In Indonesia, the oil palm estates have been developed significantly in the last 20 years. The direct extensifications toward on marginal land, especially on peat land and potential acid sulphate soils. These factuals occur due to avalability of suitable lands are shortage. Land reclamation on acid sulphate soils causes oxidation of pyritic materials and increasing soil acidity drastically and leaching some of nutrients. The objective of research was to investigate the effect of pyritic depth on chemical soil properties and oil palm production. The research was conducted by field survey in oil palm estate PTPN VII, unit Bentayan, South Sumatera. The depths of pyritic material were grouped into < 30, 30-60, and > $60 \mathrm{~cm}$. The groups plotted into every blocks in the study areas. Oil palm production and soil samples were collected for analysis. The results of the study showed that pyritic depth of $<30 \mathrm{~cm}$ influenced very significantly for increasing soil acidity, exchangeable Al, decreasing total $N$, exchangeable $K$, extracted $Z n$, and decreasing oil palm production. In other hand, soil drainage tended to decrease available $P$, exchangable $\mathrm{Ca}$ and $\mathrm{Mg}$, base saturation and extracted $\mathrm{Cu}$.
\end{abstract}

Keywords: Nutrient leaching, oil palm, pyritic depth

\section{ABSTRAK}

Pekebunan kelapa sawit di Indonesia telah berkembang secara signifikan dalam 20 tahun terakhir. Perluasan areal perkebunan kelapa sawit telah mengarah ke lahan-lahan marjinal seperti lahan sulfat masam dan gambut. Lahan marjinal untuk pengembangan perkebunan kelapa sawit bukanlah suatu pilihan, tetapi karena keterbatasan lahan semata. Reklamasi lahan sulfat masam dengan mendrain lahan rawa akan membuat kemasaman tanah meningkat drastis dan dapat mengganggu pertumbuhan tanaman. Selain itu drainase juga dapat membuat sejumlah besar hara ikut tercuci. Penelitian bertujuan untuk mengetahui pengaruh kedalaman pirit terhadap beberapa sifat kimia tanah serta produksi kelapa sawit. Penelitian dilaksanakan melalui survei lapangan di perkebunan kelapa sawit PTPN VII, unit usaha Bentayan, Sumatera Selatan. Analisis contoh tanah dilaksanakan di Laboratorium Kimia dan Kesuburan Tanah, Departemen Ilmu Tanah dan Sumberdaya Lahan, Fakultas Pertanian, IPB. Pengamatan dilakukan pada blok-blok dengan kedalaman pirit $<30 \mathrm{~cm}, 30-60 \mathrm{~cm}$, dan $>60 \mathrm{~cm}$, produksi dikumpulkan pada blok-blok tersebut dan diambil contoh tanahnya. Selain itu juga diambil contoh tanah berpirit yang belum dan telah mengalami drainase. Hasil penelitian menunjukkan bahwa kedalaman pirit $<30 \mathrm{~cm}$ memiliki pengaruh yang sangat nyata terhadap meningkatnya kemasaman tanah, Al yang dapat dipertukarkan, berkurangnya N-total, K dan Zn serta penurunan produksi tanaman kelapa sawit. Drainase menyebabkan kecenderungan terjadinya penurunan $\mathrm{kadar} \mathrm{P}, \mathrm{Ca}, \mathrm{Mg}$, dan $\mathrm{Cu}$, serta kejenuhan basa.

Kata kunci : Pencucian hara, kelapa sawit, kedalaman pirit

\section{PENDAHULUAN}

Perkebunan kelapa sawit telah menunjukkan peran yang signifikan dalam perekonomian Indonesia, terlihat dari peningkatan luas yang pesat dalam 10 tahun terakhir. Peningkatan luasan perkebunan kelapa sawit hampir dua kalinya dari tahun 2000 ke tahun 2008, yaitu dari luasan 4.1 juta hektar meningkat menjadi 7.0 juta hektar (Purba et al., 2009; Rachman dan Nurjaya, 2009). Perluasan tersebut juga mengarah ke lahan-lahan marjinal seperti lahan gambut dan lahan rawa dengan tanah asam sulfat potensial.

Perluasan areal perkebunan kelapa sawit ke lahan-lahan marjinal bukanlah pilihan, tetapi lebih merupakan tuntutan karena lahan-lahan yang lebih sesuai sangat tebatas. Pengembangan perkebunan kelapa sawit di

*Penulis Korespondensi: Telp. +628121105333; Email.atang_sutandi@yahoo.com 
lahan sulfat masam sangat dilematis, dimana untuk pertumbuhan kelapa sawit yang optimal diperlukan aerasi yang baik pada zona perakarannya, sehingga dibuat saluran-saluran drainase. Di lain pihak, dengan perbaikan drainase kondisi tanah menjadi lebih aerobik, yang menyebabkan senyawa sulfida, dikenal dengan pirit $\left(\mathrm{Fe}_{2} \mathrm{~S}_{2}\right)$, akan teroksidasi. Oksidasi senyawa pirit menghasilkan asam sulfat dan mineral jarosit dengan tingkat kemasaman yang dapat mengganggu pertumbuhan tanaman (Noor, 2004; Pons et al., 1982). Selain itu sejumlah besar hara tanaman ikut tercuci dari tanah.

Unit usaha Perkebunan Kelapa Sawit Bentayan, yang merupakan bagian dari unit usaha di bawah PTPN VII, mempunyai kandungan pirit dengan kedalaman yang bervariasi. Tingkat pertumbuhan dan produktivitas kelapa sawit juga bervariasi serta beberapa blok berada di bawah optimal. Hal ini disebabkan oleh adanya kandungan dan kedalaman pirit yang ada pada profil tanah di areal tersebut. Penelitian ini bertujuan untuk mengetahui pengaruh perbedaan kedalaman pirit pada produksi tanaman kelapa sawit dan pengaruh drainase terhadap perubahan sifat kimia tanah.

\section{BAHAN DAN METODE}

\section{Lokasi dan Waktu}

Penelitian ini dilaksanakan di perkebunan kelapa sawit unit usaha Bentayan, PT Perkebunan Nusantara VII (Persero), Sumatera Selatan. Analisis contoh tanah dilaksanakan di Laboratorium Kimia dan Kesuburan Tanah, Departemen Ilmu Tanah dan Sumberdaya Lahan, Fakultas Pertanian, IPB.

\section{Metode Penelitian}

Pengamatan kedalaman lapisan pirit ditetapkan di lapangan berdasarkan kepada $\mathrm{pH}$ hasil oksidasi oleh $\mathrm{H}_{2} \mathrm{O}_{2}$. Pada setiap blok, dengan luasan 30-40 hektar, dilakukan dua titik pengeboran dengan menggunakan bor gambut, panjang $120 \mathrm{~cm}$. Kemudian setiap lapisan profil tanah yang terambil oleh bor, diuji dengan menambah $\mathrm{H}_{2} \mathrm{O}_{2}$, bila reaksi terjadi yang ditandai dengan timbulnya buih dan diukur $\mathrm{pH}$ hasil reaksi kurang dari 2.5, maka dinilai lapisan tersebut mengandung pirit dan dicatat kedalamannya. Kedalaman pirit dikelompokan menjadi empat kelas kedalaman, yaitu (1) tidak mengandung pirit (kedalaman pirit $>120 \mathrm{~cm}$ ) atau kontrol, (2) kedalaman pirit 60-120 cm dari permukaan, (3) kedalaman pirit 30$60 \mathrm{~cm}$ dari permukaan, dan (4) kedalaman pirit $<30 \mathrm{~cm}$.

Kedalaman air tanah bervariasi tergantung pada hidrotopografi lahan dan musim, namun rata-rata kedalaman air tanah pada areal studi sekitar $50 \mathrm{~cm}$. Pada musim kemarau kedalaman air tanah berkisar dari 30 sampai $>120 \mathrm{~cm}$, sedangkan pada musim hujan berkisar dari $10-70 \mathrm{~cm}$. Pada blok dengan kedalaman pirit relatif dangkal umumnya air tanah lebih dangkal dibanding pada pirit relatif dalam.

Contoh tanah diambil pada kedalaman $20 \mathrm{~cm}$ dengan cara komposit dari 10 titik anak contoh pada blok yang diambil sampel. Kerapatan titik sampel mewakili 100 ha $\operatorname{contoh}^{-1}$, untuk dianalisis sifat kimia tanah di laboratorium. Analisis contoh tanah meliputi $\mathrm{pH}$ tanah dengan pengekstrak $\mathrm{H}_{2} \mathrm{O}$ 1:1, $\mathrm{Al}$ dapat dipertukarkan dengan pengesktrak $1 \mathrm{~N} \mathrm{KCl}, \mathrm{N}$-total metode Kjeldhal, $\mathrm{P}$ tersedia metode Bray I, basa-basa dapat dipertukarkan dan Kapasitas Tukar Kation (KTK) dengan pengekstrak $1 \mathrm{~N}$ $\mathrm{NH}_{4} \mathrm{OAC} \mathrm{pH} 7$, dan unsur hara mikro $\mathrm{Cu}$ dan $\mathrm{Zn}$ dengan pengekstrak $0,1 \mathrm{~N} \mathrm{HCl}$. Kejenuhan basa dihitung berdasarkan jumlah basa-basa dibagi dengan KTK kemudian dikalikan $100 \%$.

Untuk mengetahui pengaruh kedalaman pirit terhadap sifat kimia tanah dan produksi tanaman kelapa sawit dilakukan uji Anova yang dilanjutkan dengan Uji Duncan.

\section{HASIL DAN PEMBAHASAN}

\section{Kemasaman Tanah dan Kandungan Aluminium}

Berdasarkan hasil analisis ragam taraf nyata 5\% terlihat bahwa kedalaman pirit berpengaruh nyata terhadap nilai $\mathrm{pH}$ tanah dan $\mathrm{Al}$ dapat dipertukarkan $\left(\mathrm{Al}_{\mathrm{dd}}\right)$, rataan $\mathrm{pH}$ tanah dan $\mathrm{Al}_{\mathrm{dd}}$ pada setiap kedalaman pirit disajikan pada Gambar 1. Semakin dangkalnya pirit terlihat bahwa $\mathrm{pH}$ tanah semakin menurun dan $\mathrm{Al}_{\mathrm{dd}}$ semakin tinggi.

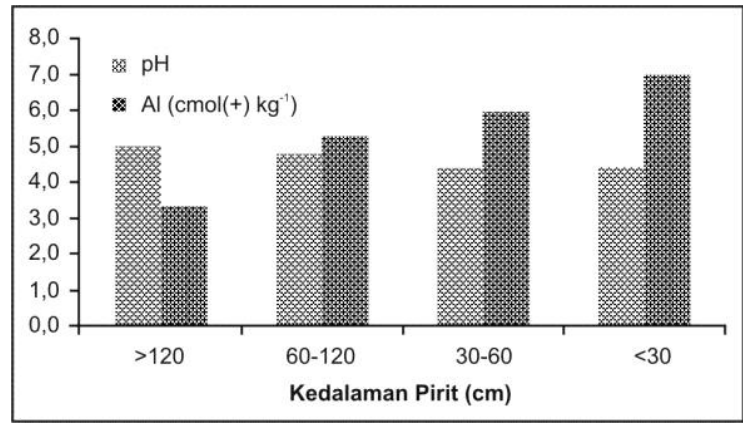

Gambar 1. Pengaruh kedalaman pirit terhadap $\mathrm{pH}$ dan $\mathrm{Al}$

Penurunan $\mathrm{pH}$ tanah dan peningkatan $\mathrm{Al}_{\mathrm{dd}}$ disebabkan adanya drainase sehingga pirit teroksidasi. Semakin dangkal lapisan pirit semakin banyak pirit teroksidasi. Reaksi oksidasi pirit disederhanakan menjadi

$\mathrm{FeS}_{2}+15 / 4 \mathrm{O}_{2}+7 / 2 \mathrm{H}_{2} \mathrm{O} \rightarrow \mathrm{Fe}(\mathrm{OH})_{3}+2 \mathrm{SO}_{4}{ }^{2-}+4 \mathrm{H}^{+}$ (Dent, 1986)

Dari persamaan reaksi tersebut terlihat bahwa setiap mol dari pirit yang teroksidasi akan menghasilkan 4 mol $\mathrm{H}^{+}$. Semakin banyaknya pirit yang teroksidasi maka $\mathrm{Al}_{\mathrm{dd}}$ juga semakin tinggi. Peningkatan $\mathrm{Al}$ disebabkan oleh dua hal, yaitu pertama adalah dengan semakin tingginya konsentrasi $\mathrm{H}^{+}$maka akan terjadi penetrasi proton kedalam lapisan oktahedral dan menukar ion $\mathrm{Al}^{3+}$ yang kemudian akan banyak dijerap pada permukaan liat (Bolt et al., 1978). Hal kedua adalah dengan semakin turunnya $\mathrm{pH}$, $\mathrm{Al}\left(\mathrm{H}_{2} \mathrm{O}\right)_{6}(\mathrm{OH})_{3}$ akan terdisosiasi menjadi 3 bentuk karena bersifat amfoter (Tan, 1986) sebagai berikut: 


$$
\begin{aligned}
& \mathrm{Al}\left(\mathrm{H}_{2} \mathrm{O}\right)_{6}{ }^{3+} \rightleftharpoons \mathrm{Al}\left(\mathrm{H}_{2} \mathrm{O}\right)_{6}(\mathrm{OH})^{2+}+\mathrm{H}^{+} \\
& \mathrm{Al}\left(\mathrm{H}_{2} \mathrm{O}\right)_{6}(\mathrm{OH})^{2+} \rightleftharpoons \mathrm{Al}\left(\mathrm{H}_{2} \mathrm{O}\right)_{6}(\mathrm{OH})^{+}+\mathrm{H}^{+} \\
& \mathrm{Al}\left(\mathrm{H}_{2} \mathrm{O}\right)_{6}(\mathrm{OH})^{+} \rightleftharpoons \mathrm{Al}\left(\mathrm{H}_{2} \mathrm{O}\right)_{6}(\mathrm{OH})_{3}{ }^{0}+\mathrm{H}^{+}
\end{aligned}
$$

\section{Kandungan Unsur Hara Makro dan Mikro}

Berdasarkan hasil analisis ragam taraf nyata 5\% terlihat bahwa kedalaman pirit berpengaruh nyata terhadap nilai $\mathrm{N}$-total tanah tetapi tidak nyata terhadap $\mathrm{P}$ tersedia dan kadar $\mathrm{Cu}$ dan $\mathrm{Zn}$, rataan hasil analisis $\mathrm{N}, \mathrm{P}, \mathrm{Cu}$ dan $\mathrm{Zn}$ pada setiap kelas kedalaman pirit disajikan pada Gambar 2. Kandungan $\mathrm{N}$-total tanah nyata semakin rendah dengan semakin dangkalnya pirit. Sementara itu $\mathrm{P}, \mathrm{Cu}$, dan $\mathrm{Zn}$ cenderung menurun dengan semakin dangkalnya pirit.

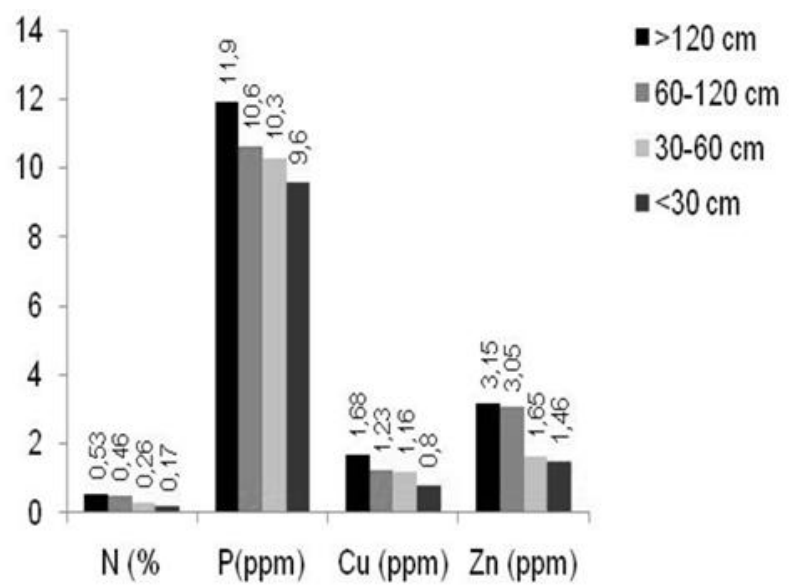

Gambar 2. Pengaruh kedalaman pirit terhadap N-total, P tersedia, $\mathrm{Cu}$, dan $\mathrm{Zn}$

Kandungan $\mathrm{N}$ total, $\mathrm{Cu}$, dan $\mathrm{Zn}$ menurun dengan makin dangkalnya pirit karena unsur-unsur tersebut tercuci oleh air drainase yang masam, sementara $\mathrm{P}$ tersedia menurun dengan turunnya $\mathrm{pH}$ dan semakin banyaknya $\mathrm{Fe}$ dan Al yang meningkat kelarutannya. Peningkatan kelarutan $\mathrm{Fe}$ dan $\mathrm{Al}$ akan mengikat $\mathrm{P}$ sehingga ketersediaan menurun.

\section{Kandungan Basa-basa Dapat Dipertukarkan}

Rataan kejenuhan basa, $\mathrm{Ca}, \mathrm{Mg}$ dan $\mathrm{K}$ dapat ditukar pada setiap kedalaman pirit disajikan dalam Gambar 3. Walaupun berdasarkan analisis ragam taraf uji $5 \%$ kedalaman pirit tidak berpengaruh nyata terhadap ketiga basa dapat ditukar tersebut, namun semakin dangkalnya pirit kandungan basa menurun. Hal ini terjadi karena oksidasi pirit menghasilkan sejumlah asam $\left(\mathrm{H}^{+}\right)$ dalam air drainase, sehingga dengan proses aksi masa maka basa-basa tertendang keluar dari komplek jerapan tanah. Seiring dengan penurunan basa-basa pada komplek pertukaran tanah maka kejenuhan basa juga menurun (Gambar 3).

\section{Perbedaan Sifat Kimia antara Tanah Berpirit yang Belum dan Telah Teroksidasi}

Untuk melihat perubahan sifat kimia setelah bahan sulfidik (pirit) teroksidasi, maka diambil bahan tanah sulfidik yang asli sebelum terokasidasi dan bahan tanah yang sudah teroksidasi sekitar 2 tahun. Dari hasil analisis dapat terlihat bahwa pada semua parameter yang diteliti, meliputi nilai $\mathrm{pH}$, C-organik, N-total, $\mathrm{Ca}, \mathrm{Mg}, \mathrm{K}$, $\mathrm{Na}$, dan KTK, tanah berpirit yang telah teroksidasi memiliki kecenderungan nilai yang lebih rendah dibandingkan dengan tanah berpirit yang belum teroksidasi. Hal ini sebagaimana disajikan pada Gambar 4. Penurunan $\mathrm{pH}$ tanah tidak begitu drastis karena analisis laboratorium tanah asli dikeringkan terlebih dahulu, sehingga sudah ada sebagian bahan sulfidik yang teroksidasi. Penurunan yang paling drastis adalah $\mathrm{K}_{\mathrm{dd}}$ dimana penurunan kadar $\mathrm{K}$ hampir seperdelapan kalinya. Hal tersebut mudah dimengerti karena $\mathrm{K}$ ion bervalensi satu sehingga mudah sekali tercuci oleh air asam.

\section{Pengaruh Kedalaman Pirit terhadap Produksi Tanaman Kelapa Sawit}

Rataan produksi setiap kedalaman pirit disajikan pada Tabel 1. Berdasarkan hasil analisis ragam taraf nyata 5\% terlihat bahwa kedalaman pirit berpengaruh sangat nyata terhadap produksi. Besarnya produksi kelapa sawit pada kedalaman pirit $<30 \mathrm{~cm}$ dan $30-60 \mathrm{~cm}$ tidak nyata, sedangkan produksi berbeda nyata pada kedalaman pirit < $30 \mathrm{~cm}$ atau 30-60 $\mathrm{cm}$ dengan produksi pada kedalaman pirit $60-120 \mathrm{~cm}$ atau $>120 \mathrm{~cm}$.

Tabel 1. Pengaruh pirit terhadap produksi tanaman kelapa sawit TM 6

\begin{tabular}{ccc}
\hline Kedalaman pirit & $\begin{array}{c}\text { Produksi } \\
\left(\mathrm{kg}^{-1} \mathrm{ha}^{-1} \mathrm{th}^{-1}\right)\end{array}$ & $\begin{array}{c}\text { \% Penurunan } \\
\text { produksi }\end{array}$ \\
\hline$<30 \mathrm{~cm}$ & $18,365 \mathrm{a}$ & 26 \\
$30-60 \mathrm{~cm}$ & $18,371 \mathrm{a}$ & 26 \\
$60-120 \mathrm{~cm}$ & $21,075 \mathrm{~b}$ & 15 \\
$>120 \mathrm{~cm}$ & $24,777 \mathrm{c}$ & 0 \\
\hline
\end{tabular}

Keterangan: Angka yang diikuti oleh huruf yang sama tidak nyata (DMRT 0.05)

Dari Tabel 1 tersebut dapat terlihat bahwa penurunan produksi pada tanah berpirit dangkal dengan $(<$ $30 \mathrm{~cm}$ dan 30-60) sebesar 26\% dibanding blok-blok dengan tanah yang kedalaman lapisan piritnya $>120 \mathrm{~cm}$. Sementara itu, penurunan produksi pada tanah berpirit dengan kedalaman 60-120 cm sebesar $15 \%$. 

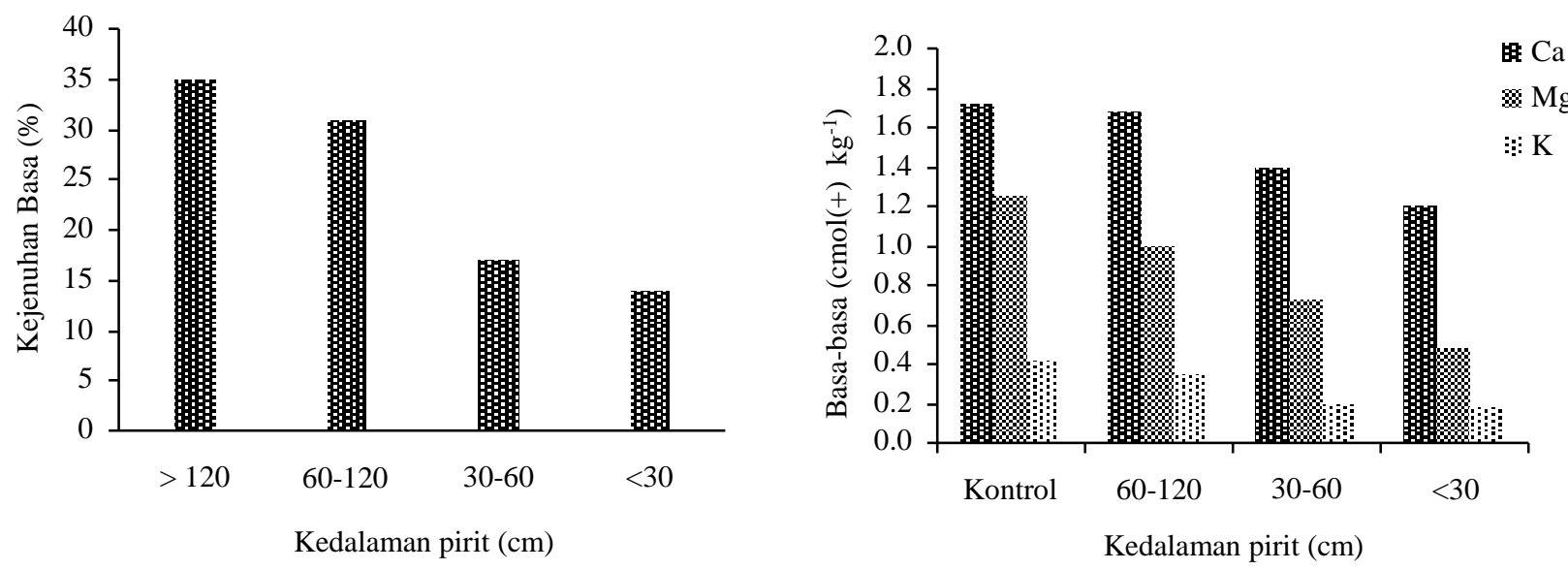

Gambar 3. Pengaruh pirit terhadap Ca, Mg, K, dan Kejenuhan Basa
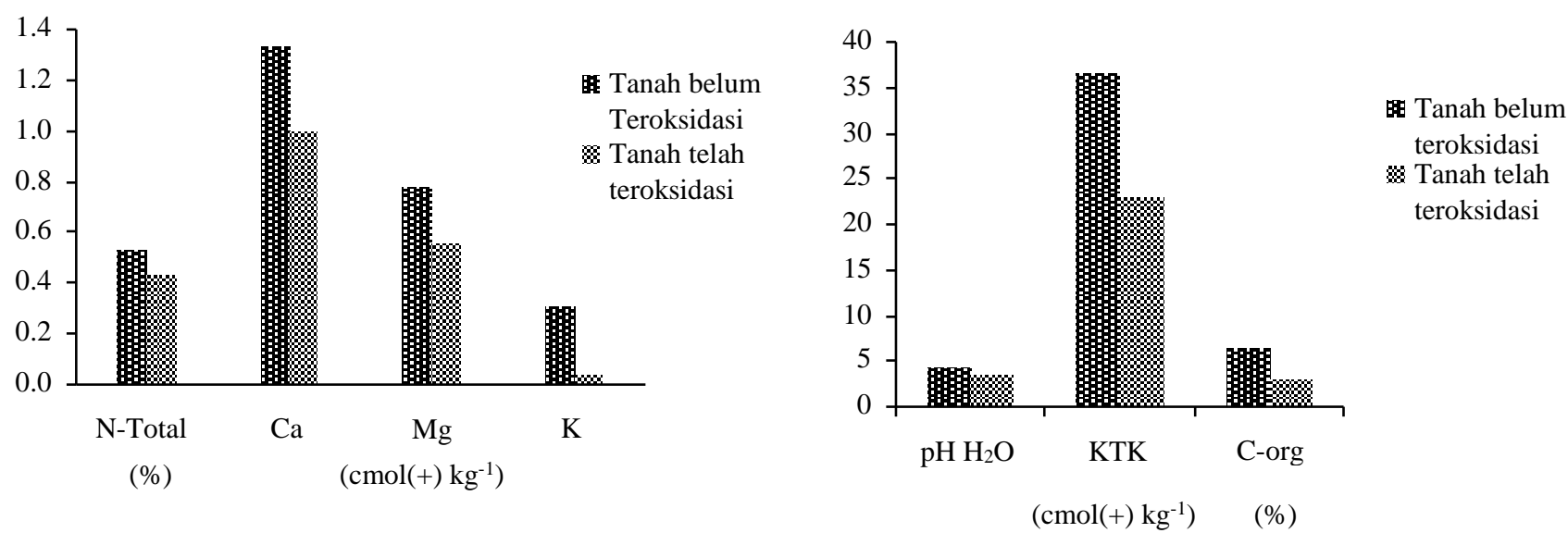

Gambar 4. Pengaruh oksidasi tanah berpirit terhadap pH, C-Organik, N, KTK, dan Basa-basa

\section{SIMPULAN}

1. Semakin dangkal pirit berpengaruh nyata terhadap menurunnya $\mathrm{pH}$ tanah dan meningkatnya $\mathrm{Al}_{\mathrm{dd}}$, serta cenderung menurunkan $\mathrm{K}, \mathrm{Ca}, \mathrm{Mg}, \mathrm{Cu}$ dan $\mathrm{Zn}$.

2. Oksidasi tanah berbahan sulfidik selama dua tahun nyata menurunkan $\mathrm{pH}, \mathrm{N}$-total, C-organik, KTK, Ca, Mg dan K.

3. Produksi kelapa sawit menurun dengan semakin dangkalnya pirit, penurunan produksi pada kedalaman pirit $<60 \mathrm{~cm}$ dan $60-120 \mathrm{~cm}$ berturut-turut adalah 26 dan $15 \%$.

\section{DAFTAR PUSTAKA}

Bolt, G.H., G.M. Bruggenwert, and A. Kamporst. 1978. Adsoprtion of cation by soil. In G.H. Bolt and G.M. Bruggenwert (Ed.) Soil Chemsitry. A Basic elements. Elsevier Scince Publishing Co., New York. p. 54-90.

Dent, D., 1986. Acid Sulfate Soils: a baseline for research and development. ILRI, Wageningen. 202p.
Noor, M. 2004. Lahan Rawa: Sifat dan Pengelolaan Tanah Bermasalah Sulfat Masam. PT Raja Grafindo Persada. Jakarta.

Pons, L. J., N.V. Breemen, and P.M. Driessen. 1982. Physiography of coastal sediment and development of potential soil acidity. In Acid Sulphate Weathering. SSSA Special Publ. No. 10. Madison. Wisconsin, USA. p. 1-18.

Purba, A. R., E. Suprinato, dan M. Arif, 2009. Peningkatan produktivitas Kelapa Sawit dengan menggunakan bahan tanaman unggul. Prosiding Pertemuan Teknis Kelapa Sawit, J.C.C. 28-30 Mei 2009. PPKS, Medan.

Rachman dan Nurjaya, 2009. Upaya peningkatan dan pencegahan peredaran pupuk palasu di perkebunan Kelapa Sawit. Prosiding Pertemuan Teknis Kelapa Sawit, J.C.C. 28-30 Mei 2009. PPKS, Medan.

Tan, K.H., 1986. Degradation of soil minerals by organic acid. In P.M. Huang and $\mathrm{M}$ Schnitzer (Ed.) Interaction of Soil Minerals with Natural Organics and Microbes. SSSA Spec. Publ. No. 17, Madison, Wsiconsin, USA. p. 1-26. 
